Criminal Justice Matters

\title{
Twelve (not so) angry men: jurors work better in small groups
}

Lorraine Hope and Bridget Waller propose a simple modification to jury deliberations

\section{Lorraine Hope \& Bridget Waller}

To cite this article: Lorraine Hope \& Bridget Waller (2011) Twelve (not so) angry men: jurors work better in small groups, Criminal Justice Matters, 86:1, 8-9, DOI: 10.1080/09627251.2011.646181

To link to this article: https://doi.org/10.1080/09627251.2011.646181

曲 Published online: 12 Dec 2011.

Submit your article to this journal

Џll Article views: 479

Q View related articles $\longleftarrow$ 


\section{Twelve (not so) angry men: jurors work better in small groups}

\section{Lorraine Hope and Bridget Waller propose a simple modification to jury deliberations}

\begin{abstract}
Twelve-person juries are often regarded as one of the cornerstones of democracy. In the UK, the right to a trial by jury is considered an important feature of the criminal justice system. Indeed, it has been rated as more important than a number of other rights, including the right to protest against the government, the right not to be detained for an extended period without charge and the right to free speech in public (Roberts and Hough, 2009). The public also trusts juries comprising randomly selected ordinary people and relies on the contribution of 12 individuals to eliminate bias and prejudice from the decision making process.
\end{abstract}

Despite unstinting support for the jury system and public confidence in one's peers to reach appropriate legal and moral decisions, jury members rarely contribute equally or efficiently to the decision making process. In reality, asking people to make a decision as a group of 12 runs counter to thousands of years of evolutionary history, over-extends the limits of our language and decision making abilities and, ultimately, restricts the ability of the jury to function effectively.

\section{Group participation}

When any group of people congregates, it typically splits into smaller groups to facilitate communication. Regardless of how many people are present in a group, conversations usually take place between smaller numbers of individuals and rarely include all members of the entire group. In fact, larger groups tend to automatically divide into smaller groups, usually composed of one speaker and up to three listeners - conversations in groups comprising more than four people are hardly ever seen in natural social interaction (Dunbar et al., 1995). Why do we see this spontaneous re-grouping? Taking an evolutionary perspective, Dunbar (1993) proposed that human language functions as an efficient alternative to social grooming in other primates, allowing us to converse with more than one individual at a time. However, our skills to engage with multiple others simultaneously remain limited. So, when more than four people attempt a conversation, it simply becomes too difficult to differentiate all the different voices involved. People are also constrained by limited processing resources - it is too cognitively demanding to maintain an efficient representation of multiple opinions and arguments. Irrespective of the mechanisms, the evidence suggests that one speaker and three listeners is the maximum conversational unit that works effectively.

\section{Decision making}

Forcing juries to have a conversation as a group of 12 , therefore, is highly unlikely to result in all 12 jurors actually taking part in the deliberation process. Without an explicit opportunity to talk in smaller groups or systematic intervention to ensure inclusion, a much smaller contingent of jurors is likely to dominate the decision making process (Hastie et al., 1983). The most likely outcome is that a strong group of individuals dominate the proceeding while more passive or reticent members make little or no contribution. Evidence bears this out. Up to a third of jurors do not actively participate during deliberations and a quarter may actually remain completely silent during jury discussions (Sanders, 1997), while the three most vocal jurors command 50 per cent of the deliberation time. Other work has revealed that jurors can feel bullied and intimidated during deliberations (see for example Tinsley, 2002). Such findings suggest that the structure of the jury discussion does not facilitate equality of contribution. More importantly, the current jury structure fails to harness the decision making power of the group. In short, this means that the jury verdict is often based on the opinions of only a handful of people, and not the decision making power of 12 'good men'.

Contribution by all jury members is important, not only to ensure the integrity of a system ideologically committed to group decision making by 'ordinary local people chosen at random' but also to facilitate optimal decisions. Group decision making is often presumed to outperform individual decision making. This presumption is at least partially premised on the notion that nonshared information (knowledge unique to certain members) will be transferred between all individuals, thus increasing the likelihood of a decision informed by all group members. Indeed, quality of decision making is associated with information exchange and information sharing positively predicts team performance. In other words, although we expect groups to make better decisions than individuals, it is unlikely that this will be the case if groups do not interact optimally. At worst, it means that a decision believed to have been reached in a systemic and democratic manner by a large group merely reflects the contribution of a (less well informed) minority.

\section{Preventing inequality}

New research conducted at the University of Portsmouth (Waller et al., 2011) suggests that the inequality embedded in the current 


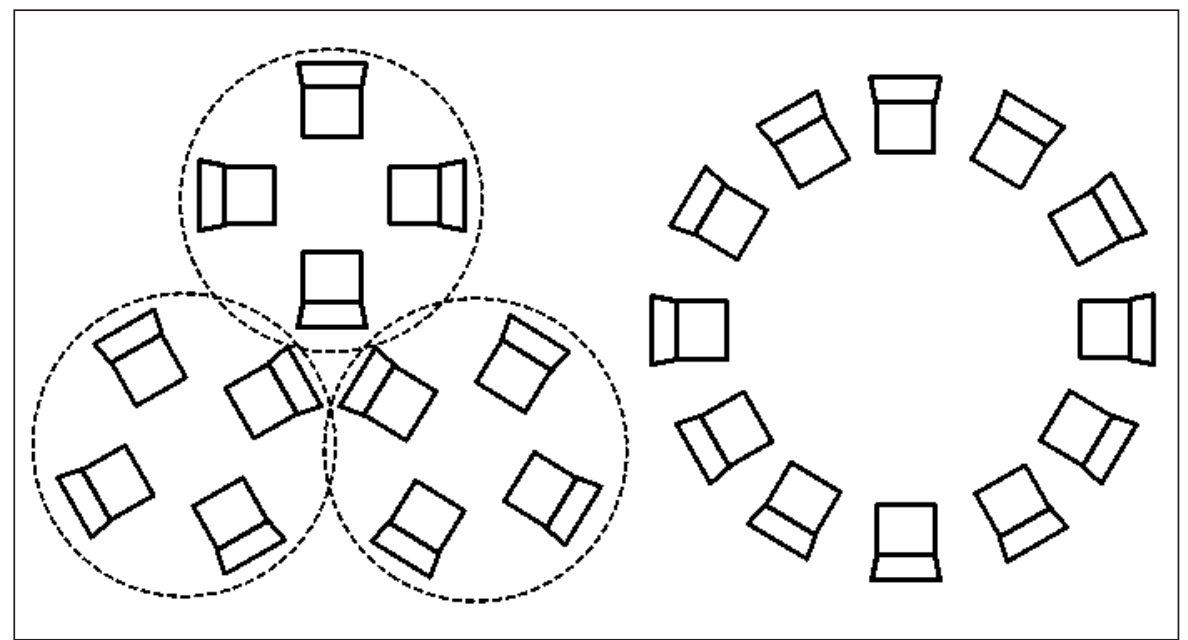

Seating arrangement in the subdivided juries compared with the traditional juries (Waller et al., 2011).

jury decision making process could be prevented by adopting a very simple modification to the way in which discussions take place. Using a mock jury paradigm, study participants observed a simulated trial before being required to reach a group verdict as a jury. Several jury groups comprising 12 members were subdivided during deliberative discussions (forming three fluid subgroups of four participants during decision making) while other groups deliberated and reached a verdict in the traditional format of 12 individuals discussing the case together. Therefore, although all juries were composed of 12 jurors, the format in which deliberations took place was manipulated. Seating in the mock 'jury room' was arranged specifically to facilitate optimal conversational units for subdivided groups (see figure above). Mock jurors in the subdivided groups reported that they had contributed more to the decision making process and felt less inhibited from engaging in discussion than mock jurors who deliberated in the traditional jury format. Thus, systematically manipulating the way in which the jury group interacted in order to mimic the grouping patterns seen in spontaneously forming conversations increased perceptions of contribution and group member satisfaction, presumably through facilitating increased discussion across the group. In contrast, within the traditional jury, members were forced into an artificially large conversational group and reported reduced engagement and involvement.

\section{Inclusive deliberation}

Why did this relatively simple modification have such a significant impact on juror perceptions of their contribution to the decision making process? Through increasing conversational participation, the subdivision process may have increased perceptions of satisfaction by inadvertently changing the mode of deliberations. In the absence of instructions to act otherwise, jury groups often engage in verdict-driven deliberations that are dominated by statements of verdict preference and involve fewer speaking participants. This mode of deliberation serves to 'create adversarial factions preoccupied with winning the point and silencing the dissenters' (Marder, 1997). In contrast, evidence-driven deliberations seek to produce a collective representation via group story construction. Ensuring that all jury members had an enhanced opportunity to contribute within smaller subgroups may have facilitated this more inclusive and efficient mode of deliberation.

Given sustained support for the jury system, a key goal in maintaining the integrity of the jury process should be to improve both the deliberative experience and its outcomes. Facilitating the contribution of all jury members rather than assuming a fair and equitable process behind closed doors is an obvious step forward. This research demonstrates that a simple manipulation to enhance the inclusivity of the decision making process, based on our understanding of group social processes, can enhance juror perceptions of engagement and contribution. Importantly, the method is not complicated or expensive, but instead simply requires jurors to be offered an alternative seating arrangement.

Further research is needed to test the underlying assumption that having greater equality within a jury also means reaching better verdicts, of course, but the findings of this initial work reveal a simple and novel way to enhance juror perceptions of their role in the decision making process.

Dr Lorraine Hope is a Reader in Applied Cognitive Psychology and Dr Bridget Waller is a Senior Lecturer at the University of Portsmouth

\section{References}

Dunbar, R. (1993), 'Coevolution of neocortical size, group-size and language in humans', Behavioral and Brain Sciences, 16, pp.681-694.

Dunbar, R., Duncan N. and Nettle, D. (1995), 'Size and structure of freely forming conversational groups', Human Nature - an Interdisciplinary Biosocial Perspective, 6, pp.67-78.

Hastie, R., Penrod, S. and Pennington, N. (1983), 'What goes on in a jury deliberation', American Bar Association Journal, 69, pp.1848-1853.

Marder, N. (1997), 'Deliberation and disclosures: a study of post-verdict interviews of jurors', lowa Law Review, 82, pp.465-491

Roberts, J. and Hough, M. (2009), Public Opinion and the Jury: an International Literature Review, Ministry of Justice Research Series 1/09, London: Ministry of Justice.

Sanders, L. (1997), 'Against deliberation', Political Theory, 25, pp.347-376.

Tinsley, Y. (2002), 'Juror decision making: a look inside the jury room', British Society of Criminology Journal, 4 (e-journal), www.britsoccrim.org/ volume4/004.pdf

Waller, B., Hope, L., Burrowes, N. and Morrison, E. (2011), 'Twelve (not so) angry men: managing conversational group size increases perceived contribution by decision makers', Group Processes and Intergroup Relations. 